\title{
Pharmacogenetics of antipsychotic adverse effects: Case studies and a literature review for clinicians
}

\author{
Adriana Foster' \\ Zixuan Wang ${ }^{2}$ \\ Manzoor Usman' \\ Edna Stirewalt ${ }^{\prime}$ \\ Peter Buckley' \\ 'Department of Psychiatry and \\ Health Behavior and ${ }^{2}$ Department \\ of Medicine and Pathology, Medical \\ College of Georgia, Augusta, GA, USA
}

\begin{abstract}
There is a growing body of literature supporting the contribution of genetic variability to the mechanisms responsible for the adverse effects of antipsychotic medications particularly movement disorders and weight gain. Despite the current gap between research studies and the practical tools available to the clinician to identify such risks, it is hoped that in the foreseeable future, pharmacogenetics will become a critical aid to guide the development of personalized therapeutic regimes with fewer adverse effects. We provide a summary of two cases that are examples of using cytochrome $\mathrm{P} 450$ pharmacogenetics in an attempt to guide treatment in the context of recent literature concerning the role of pharmacogenetics in the manifestation of adverse effects of antipsychotic therapies. These examples and the review of recent literature on pharmacogenetics of antipsychotic adverse effects illustrate the potential for applying the principles of predictive, preventive, and personalized medicine to the therapy of psychotic disorders.
\end{abstract}

Keywords: pharmacogenetics, adverse effects, antipsychotic drugs

\section{Introduction}

Antipsychotic drugs are widely prescribed for a multitude of psychiatric conditions. Approximately 36 million antipsychotic prescriptions were written in the United States in ambulatory care from 1997-2000 (Van Brunt et al 2003). In 2002 over one million prescriptions for antipsychotics were written for children and adolescents in ambulatory care (Olfson, Blanco et al 2006). There are significant risks associated with first and second-generation antipsychotics: weight gain, diabetes, hyperlipidemia particularly with the second-generation drugs (Haro et al 2006; Lambert et al 2006; Olfson, Marcus et al 2006), movement disorders (Joy et al 2006; Shirzadi et al 2006), hyperprolactinemia and cardiovascular adverse effects. It is unknown if these risks compound when antipsychotics are prescribed in combinations (Freundreich et al 2002; Stahl et al 2004). Intolerable adverse effects and lack of efficacy contribute to a significant proportion of antipsychotic discontinuations (Lieberman 2005).

Pharmacogenetics explores the role of genetic factors in predicting drug response and potential side effects while pharmacogenomics explores the relationship between whole genome factors, drug response and potential side effects (Malhotra et al 2004; Lane et al 2005). The relatively new field of pharmacogenetics studies pharmacokinetic and pharmacodynamic candidate genes.

Genes coding for proteins at which a drug acts are known as pharmacodynamic genes. Polymorphisms [genetic variations which occur with a frequency of $1 \%$ or more in population] of genes coding for dopamine and serotonin receptor and transporter proteins became obvious study candidates, based on the putative role of these neurotransmitters in the mechanism of action of first and second generation antipsychotics (Malhotra et al 2004). The pharmacodynamic genes are difficult to study partly because their measurable genetic effects (phenotypes) are clinical characteristics, which can be subject to the interaction between genes and environment.
Correspondence: Adriana Foster Department of Psychiatry and Health Behavior, Medical College of Georgia, I5I 5 Pope Ave, Augusta, GA 30912, USA $\mathrm{Tel}+\mid 7067217488$

Fax+l 7067211793

Email afoster@mcg.edu 
The pharmacokinetic genes contribute to the differences in plasma level or tissue distribution of drugs. Examples of pharmacokinetic genes are those coding for cytochrome P450 (CYP450), a set of enzymes involved in the first phase of metabolism of many antipsychotics. Some of CYP450 genes are highly polymorphic and it is thought that their variations can contribute to side effects of antipsychotics. The function of these genes is known, and the phenotypes resulted from their polymorphisms can be characterized by measuring drug metabolic ratios (Dahl 2002). Numerous authors suggested that genotyping for families of CYP450 enzymes (2D6, 2C19) could potentially aid in prescribing antipsychotic drugs (Dahl 2002; Kirchheiner 2004; de Leon, Armstrong et al 2006; Murray 2006). Cytochrome P450 (CYP450) microsomal enzymes mediate approximately $80 \%$ of the oxidative drug metabolism. More than $50 \%$ of the drugs responsible for adverse drug reactions are metabolized by polymorphic phase-one metabolism enzymes and of these, $86 \%$ are CYP450 (Ingelman-Sundberg 2004). One or more CYP450 enzymes may contribute to the oxidative metabolism of a given drug (for example, aripiprazole is a substrate for CYP450 2D6 and 3A4 whereas risperidone is a major substrate for CYP450 2D6). CYP450 1A2 and 3A4 are important in metabolism of antipsychotics (Dahl 2002; de Leon, Armstrong et al 2006) but individual genetic factors are yet to be clearly recognized in the activity of these enzymes (Ingelman-Sundberg 2004; Wilkinson 2005). CYP2D6 metabolizes many psychotropic drugs, including antipsychotics like haloperidol, thioridazine, perphenazine, chlorpromazine, risperidone, and aripiprazole as outlined in excellent reviews (Dahl 2002; Ingelman-Sundberg 2004; Murray 2006). CYP2D6 is a highly polymorphic gene with more than 70 variants, resulting in four phenotypes. Extensive metabolizers (EMs) have one or two functional copies of the CYP2D6 gene and have normal metabolic rate of 2D6 substrates. Intermediate metabolizers (IMs) have one nonfunctional allele and one low activity 2D6 allele leading to lower than normal metabolic rate of substrates; in presence of a CYP2D6 inhibitor, the metabolic rate of substrates will be further reduced. Poor metabolizers (PMs) have two non-functional 2D6 alleles leading to no 2D6 activity and thus increased risk of adverse effects. Ultrarapid metabolizers (UMs) have three or more copies of a functional 2D6 gene; they metabolize substrates rapidly and may have limited clinical response at standard doses of drugs. Metabolizer categories have variable distribution between ethnic groups for example $5 \%-10 \%$ of Caucasians are poor metabolizers while $29 \%$ of North Eastern Africans and Middle Easterners are ultrarapid metabolizers (Bradford 2002; Ingelman-Sundberg 2004, de Leon, Armstrong et al 2006).

We will illustrate two clinical cases, which reflect the burden of antipsychotic adverse effects and we will make an attempt to summarize aspects of pharmacogenetics related to antipsychotic tolerability.

\section{Methods}

Institutional review board approval was obtained to retrospectively review records on a group of patients genotyped for CYP450 with the FDA approved AmpliChip ${ }^{\text {TM }}$ P450 test (Roche Diagnostics, Indianapolis, Indiana, USA) at Georgia Esoteric and Molecular Lab, as part of their routine clinical care in our clinic. We chose two cases to illustrate the burden of antipsychotic adverse effects.

\section{Case A}

Ms. A is a Caucasian female with bipolar I disorder. The patient was referred by neurology where she was seen for sedation, ataxia, vertigo, diplopia and headache, considered to be adverse effects from her psychotropic medication, lamotrigine at the time. The side effects ceased after lamotrigine was discontinued. On initial evaluation she presented with irritable, labile, agitated mood, lack of sleep and racing thoughts. Medical and neurological studies including a computerized tomography of the brain were unremarkable. In the past, patient has been treated with divalproex sodium, leading to weight gain, as well as carbamazepine and oxcarbazepine, which were ineffective. Risperidone caused her profound sedation and was discontinued quickly. Ms. A presented to the clinic on lithium $900 \mathrm{mg}$ /day (at therapeutic level) and clonazepam $6 \mathrm{mg} /$ day. Aripiprazole $5 \mathrm{mg}$ daily was added for mood instability and was titrated up to $15 \mathrm{mg}$ daily. On the subsequent visit Ms. A reported restlessness and urge to move constantly. Her symptoms of akathisia resolved after aripiprazole was discontinued. CYP450 genetic testing revealed CYP2D 6 genotype $* 3 / * 5$ with predicted phenotype of poor metabolizer and CYP2C19 genotype $* 1 / * 1$ with predicted phenotype of extensive (normal) metabolizer. The patient eventually stabilized on lithium, clonazepam and topiramate.

\section{Case B}

Ms. B is a Caucasian female with schizophrenia. Ms. B initially presented on a combination of ziprasidone 120-mg daily, olanzapine $5 \mathrm{mg}$ at bedtime, trazodone $100 \mathrm{mg}$ at bedtime and benztropine $2 \mathrm{mg} /$ day. Due to dizziness and sedation Ms. B was tapered off ziprasidone and olanzapine 
and transitioned to quetiapine. Trazodone was discontinued. Over the next month, as the patient transitioned between antipsychotics and quetiapine was titrated to $400 \mathrm{mg}$ daily she had excessive sweating, tachycardia and neck pain, gained approximately 20 pounds and had hallucinations. Benztropine was continued for suspected residual extrapyramidal side effects from ziprasidone. Five months later, quetiapine was tapered and discontinued and ziprasidone reintroduced due to significant weight gain on quetiapine. On ziprasidone $100 \mathrm{mg}$ daily, Ms. B lost 15 pounds but developed muscle stiffness, cogwheeling, tremor and night sweats. When benztropine was added she developed blurry vision. After five more months, Ms. B was switched from ziprasidone to aripiprazole. Over the next 8 months Ms. B gradually began to experience sedation, gained fifteen pounds, she developed difficulty with her gait, stiffness, cogwheeling and dyskinetic ocular movements. Her CYP450 genetic testing revealed CYP2D6 genotype $* 1 / * 41$ with predicted phenotype extensive metabolizer and CYP2C19 genotype *1/*2 with predicted phenotype extensive metabolizer.

\section{Discussion}

The only FDA-approved pharmacogenetic test clinically available to our two patients was AmpliChip ${ }^{\text {TM }}$ CYP450, which genotypes patients for CYP450 enzymes 2D6 and 2C19. The AmpliChip P450, which was the first microarraybased test cleared by FDA, provides a highly comprehensive assessment of cytochrome P450 2D6 and 2C19 genotypes and detects the most common 20 CYP2D6 and 3 CYP2C19 alleles. This test also differentiates the presence of multiple copies of functional or non-functional CYP2D6 gene, which is important to identify true ultrarapid metabolizers. Using this approach, patient $\mathrm{A}$ was found to have $* 3$ and $* 5$ for $2 \mathrm{D} 6$ and allele $* 1$ and $* 1$ for $2 \mathrm{C} 19$ and patient $\mathrm{B}$ was found to have $* 1$ and $* 41$ for 2 D6 and $* 1$ and $* 2$ for $2 \mathrm{C} 19$. This approach is effective in detecting inactive genotypes caused by mutations (ie, CYP2D6 *3 and CYP2C19*2) and gene deletion (ie, CYP2D6 *5) and genotypes associated with decreased activity of CYP2D6 enzyme (ie, CYP2D6 *41). The strength of this approach is the capability of the software to automatically express the complex genotypes in terms of four functional phenotypes for 2D6.

In case A, testing showed that the patient is a CYP 450 2D6 poor metabolizer, which may explain her reactions to risperidone and aripiprazole, since both of these antipsychotics are metabolized by CYP450 2D6. In case B, from the antipsychotics tried by the patient, the only major substrate for 2D6 was aripiprazole, although CYP450 2D6 has been implicated as a minor metabolic pathway for other antipsychotics including olanzapine and quetiapine (Dorado et al 2006). She is a CYP450 2D6 extensive (normal) metabolizer. In her case, CYP450 testing sheds no light on her remarkable history of sedation, weight gain and motor adverse effects from antipsychotics.

\section{Association of genetic variations in CYP450 enzymes with antipsychotic treatment adverse effects}

Did the patients' test results influence our clinical decisions about their treatment with antipsychotics in the two cases described?

Risperidone is metabolized in the liver, through hydroxylation to 9-hydroxyrisperidone by the CYP2D6 enzyme. The CYP2D6 PM phenotype was cited to correlate with risperidone side effects and discontinuation (de Leon, Susce et al 2005a). Risperidone steady state plasma concentration was shown to differ widely between 2D6 ultrarapid and poor metabolizers (Scordo et al 1999). Aripiprazole is metabolized by dehydrogenation, hydroxylation, and N-dealkylation. CYP3A4 and CYP2D6 enzymes are thought to be responsible for dehydrogenation and hydroxylation of aripiprazole, while N-dealkylation is catalyzed by CYP3A4. There is little published information about the effect of CYP450 2D6 PM status on clinical effects of aripiprazole. In their review, Swainston-Harrison and Perry (2004) mention 60\% higher exposure of CYP2D6 PM's to total active moiety (aripiprazole and dehydro-aripiprazole) and almost double elimination half-life for PMs compared to EMs (146 vs 75 hours). No dosage adjustments are recommended for the 2D6 PMs in the manufacturer's prescribing information but the document advises adjusting aripiprazole dose in presence of inhibitors and inducers of CYP450 2D6 [Bristol-Myers Squibb Company and Otsuka Pharmaceutical, Inc. Abilify ${ }^{\mathrm{TM}}$ prescribing information, www.abilify.com accessed 2/16/07]. In a large naturalistic non-controlled study of two groups, patients treated with risperidone and patients who discontinued treatment with risperidone in a state hospital, the 2D6 PM phenotype appeared to increase the individual risk of adverse drug reactions from risperidone 2.5 times. However, across the entire population treated with risperidone in the same study, only $10 \%-20 \%$ of the adverse reactions were explained by the CYP450 2D6 PM status (de Leon, Susce et al 2006). Similarly, Brockmoller et al (2002), showed that that the risk of extrapyramidal side effects from haloperidol was significantly higher in poor metabolizers of 2D6 but found that genotyping would prevent side effects in only $5 \%$ of 
the people treated with haloperidol. There are limited but intriguing data showing that the cost of treating CYP2D6 PM and UM patients is significantly higher than that of treating patients with intermediate and extensive metabolizer phenotypes (Chou et al 2000). As it will be further shown in the section dedicated to tardive dyskinesia, CYP2D6 polymorphisms have been primarily associated with movement adverse effects from antipsychotics. In contrast with the limited guidance found in the medication prescription information, several sources offer dosing guidelines for antipsychotics with respect to use of concomitant competitive substrates, inhibitors and inducers of CYP450 enzymes, as well as use in the case of patients with CYP450 genetic polymorphisms (Kirchheiner 2004; de Leon, Armstrong et al 2005, 2006). Based on these published guidelines, in case A, if an antipsychotic is absolutely necessary, it would be reasonable to either prescribe antipsychotics not dependent of CYP450 2D6 such as clozapine, olanzapine, quetiapine or ziprasidone or use very low doses of 2D6-dependent antipsychotics. However, a clinician approaching case $\mathrm{B}$ has no available tools to guide him/her in the efforts to personalize this patient's treatment, even in face of her extensive history of antipsychotic side effects.

A preponderance of pharmacogenetic studies of antipsychotics adverse effects addressed movement disorders (particularly tardive dyskinesia) and weight gain. Much less information is available about hyperprolactinemia, neuroleptic malignant syndrome and cardiovascular effects of antipsychotics.

\section{Pharmacogenetic studies of treatment-emergent movement disorders with antipsychotics}

Extrapyramidal adverse effects of antipsychotics have been attributed to dopamine (D2) receptor blockade exceeding 80\% (Kapur and Seeman 2001) and subsequently polymorphisms of genes coding for the dopamine D2 receptor family, which includes D2, D3 and D4 were studied extensively. Acute extrapyramidal effects including Parkinsonism, dystonia and akathisia have been the subject of very few pharmacogenetic studies: Mihara, Kondo et al (2001) and Kaiser et al (2002) found no association of D2 receptor polymorphisms with these side effects.

Akathisia, described by Barnes (1992) as a subjective feeling of restlessness, urge to move constantly and dysphoria, is frequently present with first generation antipsychotic agents, but $7 \%-8 \%$ patients experience it with second generation agents like risperidone and aripiprazole (Janssen L. P.
Risperdal ${ }^{\circledR}$ prescribing information accessed 3/19/07 http:// www.risperdal.com/active/janus/en_US/assets/common/ company/pi/risperdal.pdf and Swainston-Harrison 2004). Akathisia has been regarded as a possible precursor of tardive dyskinesia (Eichhammer et al 2000) and its severity was related to tardive dyskinesia (TD) in the CATIE study (Miller, McEvoy et al 2005). Eichhammer et al (2000) reported that homozygotes for the Ser9Gly variant of dopamine DRD3 gene polymorphism had significantly higher incidence of akathisia than patients who were not homozygotes, after two weeks of treatment with haloperidol or equivalent.

TD is a hyperkinetic, purposeless, repetitive, persistent drug induced movement disorder which occurs in $20 \%-30 \%$ of patients with prolonged antipsychotic treatment (Chouinard 2004) and it has been a major focus of antipsychotic pharmacogenetic studies. CATIE study confirmed that risk of tardive dyskinesia is associated to patient's age, duration of antipsychotic exposure, exposure to conventional antipsychotics, anticholinergic medications, substance abuse, presence of extrapyramidal side effects and akathisia (Miller, McEvoy et al 2005). In addition to these known predictors, it is believed that a genetic component contributes to development of TD. Based on animal studies, pathophysiology of TD was attributed to up-regulation of the dopamine receptors and their hypersensitivity due to dopamine blockade by antipsychotic drugs (Casey 2004). Here again, the dopamine D2-family of receptors have been the focus of pharmacogenetic studies, along with serotonin receptor polymorphisms and hepatic isoenzyme genes.

Although DRD2 has long been hypothesized to be the main target for antipsychotic medications, only a few of its polymorphisms have been investigated for their potential association with TD. Zai et al (2006) showed that from 12 polymorphisms found on the DRD2 gene in a European Caucasian $(n=202)$ and African-American $(n=30)$ sample of patients with TD, only C957T and the adjacent C939T were significantly associated with TD but not with its severity.

Steen (1997), Basile (1999), Segman (1999), Lerer (2002), de Leon, Susce et al (2005b) and others investigated the single nucleotide substitution which exists in the first exon (coding sequence) of the D3 receptor gene, resulting in a serine to glycine (Ser9Gly) aminoacid change in the amino acid sequence of the receptor protein. All found independently that the Ser9Gly DRD3 polymorphisms homozygous for glycine or containing the glycine allele are associated with increased the risk for TD. Other authors (Inada et al 1997; Rietschel et al 2000 and Garcia-Barcelo et al 2001) did 
not find association of DRD3 Ser9Gly polymorphism and TD. Interestingly, Jeanneteau et al (2006) demonstrated in a French sample that Ser9Gly variant of DRD3 was associated with risk and age at onset of essential tremor, a movement disorder unrelated to antipsychotic use. Although researchers recognized and attempted to control for variables like age, sex ethnicity and history of antipsychotic treatment it is likely that the contradictory findings are related to these variables as well as the sample sizes and the differences in the study designs. Srivastava et al (2006) studied 24 polymorphisms on six dopaminergic genes, dopamine receptors DRD1, DRD2, DRD3, DRD4, DAT (dopamine transporter) and COMT (cathecol-O-methyltrasferase) in North Indian patients with schizophrenia. Only markers on DRD4 and COMT genes associated with TD in this patient population.

The association of serotonin receptor markers with TD was also explored. Segman et al (2001), Tan et al (2001), and Lerer et al (2005) found significant associations of markers (genotypes and haplotypes) of the 5-HT2A receptor with TD but Basile et al (2001) did not replicate the findings (a haplotype is a combination of alleles at closely linked gene loci on same chromosome (Malhotra et al 2004)).

In their review, Reynolds et al (2005) showed that serotonin receptor $5 \mathrm{HT} 2 \mathrm{C}$ polymorphisms were associated with TD in various ethnic populations treated with antipsychotics. Polymorphisms of metabolic enzymes like CYP450 genes CYP450 2D6, 1A2, 3A4, were studied to explore their potential association with TD. Kapitany et al (1998), Ohmori et al (1998), and Ellingrod et al (2000) found that polymorphisms of CYP450 2D6 resulting in reduced activity of this enzyme correlated positively with higher AIMS (Guy 1976) scores and the development of TD. Tiwari et al (2005) studied the association of CYP450 3A4 and 2D6 polymorphisms with $\mathrm{TD}$ in an Indian population. Despite of its highly variable expression, CYP450 3A4 functional polymorphisms are not clearly understood and $3 \mathrm{~A} 4 * 1 \mathrm{~B}$ variant is no exception. Both CYP450 3A4*1B and 2D6*4 failed to show association with risk of TD. de Leon, Susce et al (2005b) studied the association between tardive dyskinesia and genetic variations of pharmacokinetic genes, CYP2D6 or CYP3A5, pharmacodynamic genes, DRD2 and DRD3, glutathione S-transferases (GSTT1 and GSTM1) which could be implicated in oxidative stress (and therefore possibly in TD mechanism) on white and African American mentally ill patients from Kentucky. Similar to the Indian sample (29\%), 31\% of people from the sample studied by de Leon had TD. In addition to the DRD2 results discussed above, gluthatione S-transferase M deficiency associated with TD particularly in white women and there was a trend of association between 2D6 PM phenotype and TD.

Ellingrod and colleagues (2002) studied prospectively patients with schizophrenia genotyped for CYP2D6*1, $* 3$, and $* 4$ alleles, and collected data on their psychiatric symptoms, cigarette smoking status, and antipsychotic drug exposure. While no homozygotes were found for *3 or $* 4$ genotypes, the group of smokers with heterozygous CYP2D6 $* 3$ or $* 4$ genotype had the highest proportion of tardive dyskinesia (78\%) compared with 2 D6 *1/*1 smokers or non-smokers $(20 \%-33 \%)$. The authors concluded that patients with a low CYP2D6 activity due to presence of $* 3$ or *4 alleles may shunt antipsychotic metabolism through other pathways (for example CYP450 3A4) that are induced by cigarette smoking and that the induction may in turn result in formation of neurotoxic metabolites, possibly explaining higher frequency of tardive dyskinesia. Sachse et al (1997) found that the CYP2D6 polymorphisms did not predict TD but that the CYP1A2 polymorphisms were significantly associated with TD. A polymorphism of CYP1A2 gene was significantly associated with TD severity in a study by Basile et al (2000) with even more pronounced effect in the smoker group of the sample of Caucasians and African Americans, while Schulze et al (2001) did not replicate these results in a German sample.

\section{Pharmacogenetic studies of antipsychotic-related weight gain}

Among the metabolic disturbances associated with the use of antipsychotic drugs, weight gain has come to the attention of patients, families, care providers and the general public especially with the development of second-generation antipsychotic drugs. Little is known about risk of obesity or diabetes in patients with schizophrenia independent of antipsychotic treatment (Regengold et al 2001; Ryan et al 2003). In contrast, there is abundant information about the association of antipsychotic treatment with risk of obesity, cardiovascular disease and their dire consequences on general health and life expectancy (Hennekens et al 2006; Newcomer 2006; Sipos et al 2006). While risks of weight gain are defined for various antipsychotics (Müller and Kennedy 2006) front line practitioners have limited tools to predict why some patients develop obesity and diabetes and others do not when prescribed the same antipsychotic drugs. This individual variability can only lead one to suspect that the interaction of genes and environment is heavily illustrated in this area. Müller and Kennedy (2006) list lower body mass index (BMI) at treatment onset as predictor of 
weight gain for all antipsychotics, rapid and early weight gain with olanzapine as predictors of long term weight gain and similar BMI changes in monozygotic twins treated with same antipsychotic as available predictive tools.

Serotonin and leptin are two substances targeted by pharmacogenetic studies of antipsychotic induced weight gain. Serotonin's role in feeding behavior was clarified by Tecott et al (1995) who showed that mice lacking functional serotonin 2C (5HT2c knockout mice) receptors were prone to increased feeding and weight gain. Leptin is a peptide secreted by fat cells in proportion to the body fat content and its higher serum levels decrease food intake and fat storage through action on hypothalamic nuclei (Muller and Kennedy 2006). Second generation antipsychotics especially clozapine and olanzapine bind to the $5 \mathrm{HT}_{2} \mathrm{C}$ receptors and genetic variations of these receptors were studied in the attempt to understand the individual and racial differences in weight gain with antipsychotics.

In their review Reynolds et al (2005) summarize their own positive association studies between the $5 \mathrm{HT}_{2} \mathrm{c}-759 \mathrm{C} / \mathrm{T}$ single nucleotide polymorphisms and weight gain in antipsychotic naïve first episode Chinese Han patients treated with chlorpromazine and risperidone and later with clozapine. Reynolds et al (2005) also cite other studies which found no association between the 5HT2c Cys23Ser polymorphism and weight gain from clozapine in Chinese and Caucasian and African Americans. Ellingrod et al (2005) and Miller, Ellingrod et al (2005) found that subjects with schizophrenia without the 5-HT2C-759T allele were at a higher risk of gaining weight during treatment with olanzapine and respectively clozapine. Templeman et al (2005) studied polymorphisms of the both the serotonin 5-HT2C receptor and the leptin genes and their association with BMI and plasma leptin levels in Caucasian patients at 6 week, 3 and 9 months of treatment with various antipsychotic drugs. Consistent with other studies, they found subjects with 5-HT2C-759T allele had significantly less weight gain than those without this allele. The leptin polymorphism studied $(-2548 \mathrm{~A} / \mathrm{G})$ was not associated with short-term weight gain but showed significant association with antipsychotic-induced weight gain at 9-months. The 5-HT2C-759 genotype was significantly associated with pre-treatment plasma leptin levels. Ellingrod et al (2007) re-analyzed the patient sample from their previous study (Ellingrod et al 2005) for -2548G/A polymorphism of the leptin gene and Q223R A to G transition of the leptin receptor. They found a significant relationship between alleles of the leptin and leptin receptor, olanzapine plasma concentrations and BMI. Subjects with at least one $\mathrm{G}$ allele at each locus had a threefold increase in BMI at olanzapine concentrations higher than $20.6 \mathrm{ng} / \mathrm{ml}$. Authors postulated that a combination of impaired leptin expression and leptin receptor insensitivity may increase the risk of weight gain, especially in presence of antipsychotic drugs.

Pharmacogenetic studies of antipsychotic related hyperprolactinemia are few, as reported by Reynolds et al (2006) in their review article. Mihara, Suzuki et al (2001) showed that a polymorphism of the dopamine D2 receptor gene Taq 1 has been associated with greater prolactin response to bromperidol in female carriers of the A1 allele of this polymorphism on a Japanese sample of patients with schizophrenia and concluded that such patients may be at high risk for adverse effects associated with neuroleptic-induced hyperprolactinemia. Young et al (2004) replicated this finding in a larger population of patients with various diagnoses stable for at least one month on various antipsychotic drugs. Their patients were divided in 4 groups [clozapine, olanzapine, first generation antipsychotics (FGA) and risperidone]. Patients in the FGA group with Taq 1 A1 allele had prolactin levels $40 \%$ higher and patients in the clozapine group had prolactin levels twice as high as those without the A1 allele.

Neuroleptic malignant syndrome (NMS) is a rare $(0.02 \%-2 \%)$ complication of antipsychotic treatment but its mortality rate is $20 \%-30 \%$ (Wilkaitis 2004). Suzuki et al (2001) found an association between the Taq 1 A1 allele and the risk of developing NMS in Japanese patients with schizophrenia and replicated their own findings in another study (Mihara et al 2003). In the latter study they also genotyped the subjects for the 141C Ins/Del D2 polymorphism and for the Ser(9)Gly polymorphism of dopamine D3 receptor, none of which were found to be associated with the risk of TD. Del Tacca et al (2005) reported a case in which a Caucasian patient diagnosed with NMS after taking risperidone and citalopram has been genotyped as heterozygous for dopamine D2 Taq1 A1 allele. Kishida et al (2004) reported an association between 141C Ins/Del D2 polymorphism and NMS but did not find an association of the syndrome with D2 Taq1 A1 and the Ser(9)Gly polymorphism of dopamine D3 receptor.

\section{Pharmacogenetics of antipsychotic cardiovascular side effects}

QT interval prolongation is a warning sign for potentially life threatening Torsade de Pointes arrhythmia. Llerena et al (2004) studied a sample of white Europeans treated with risperidone and demonstrated that the QTc interval was longer in the subjects with one active CYP450 2D6 gene compared with subject with two active genes. In their 
review, Dorado et al (2006) describe that the number of CYP 450 2D6 active genes was correlated with the QTc interval lengthening in patients treated with thioridazine and conclude that CYP450 2D6 phenotype and genotype must be taken into consideration in treatment with patients with other risk factors for long QT for example heart disease, congenital long QT, elderly.

There are significant obstacles in face of clinical applications of pharmacogenetics. As frequently shown in our review, studies are difficult to replicate likely because of sample size and ethnic variation of the genetic polymorphisms studied. The phenotypes studied to measure the effect of pharmacodynamic genes are clinical characteristics. Such measurements can vary due to raters and due to intra-individual differences at various times in same patient. In addition, the interpretation of the association between identified polymorphisms and the adverse effects is not always straightforward. Since they change the protein sequences, the interpretation of mutations in the coding regions of pharmacodynamic genes is obvious. The mutations on the non-coding regions of a gene could potentially change the property of the gene product by regulating the transcription process, the splicing, and the stability of the mRNA. Further more, the polymorphism or mutation identified in the non-coding region of a gene may not be responsible for the phenotype directly but may be linked to an unknown mutation located close to the studied polymorphism. The phenotype is the result of the interaction between genes and environment. In addition, the genes can have additive effect or even interact with each other. In this case, a certain polymorphism may have a functional effect on the phenotype in presence, but not in absence of another polymorphism (Lerer and Segman 2006).

Intermediate phenotypes measured with functional imaging have been proposed (Blasi et al 2006) but they can be difficult to apply in large patient samples and only add to the cost of already expensive pharmacogenetic testing.

Clinical applications of pharmacogenetic testing also faces considerable ethical and economic challenges. Most of the genetic polymorphisms described on our literature review are not available for testing outside academic research centers. However, some tests like AmpliChip P450 aimed at predicting CYP2D6 and 2C19 gene polymorphisms are cleared by FDA and are available commercially. However if such tests are not linked to a particular disease or a particular drug, their penetration in clinical practice may be difficult (Williams-Jones et al 2007). Understandably, clinicians may be hesitant to apply pharmacogenetic testing as long as the regulation of various tests varies (Morley and Hall 2004), and there are no guidelines based on large sample sized studies to document their utility at the point of patient care (Ozdemir et al 2007). There is concern that certain individuals or populations who harbor disadvantageous polymorphisms may be discriminated against (Morley and Hall 2004). In the US the House of Representatives passed The Genetic Information Nondiscrimination Act (HR 493) in 2007, which aims to prevent the use of genetic information to deny a person health insurance or job opportunities and makes it illegal for health insurance plans or to deny coverage to people based on a genetic predisposition to a disease. This bill is now considered in the US Senate.

\section{Conclusions}

Clinicians treating severe mental illness are eager to expand their understanding of the effects of antipsychotic treatment. We summarized here advances in pharmacogenetics, a field that aims to help individualize treatment with antipsychotic drugs, to target optimal response and avoid risk of adverse effects. Drug response and tolerability are complex phenomena which involve additive and interactive effects of genes as well as multiple other factors like age, sex, ethnicity, concomitant disease, liver and kidney function, diet, smoking, pregnancy and drug-drug interactions. It is thus understandable that the clinical applications of pharmacogenetics are developing and penetrating into practice slowly and most likely will compliment but not replace clinical monitoring of antipsychotics.

\section{References}

Barnes TRE. 1992. Clinical assessment of the extrapyramidal side effects of antipsychotic drugs. J of Psychopharmacology, 6:214-21.

Basile VS, Masellis M, Badri F, et al. 1999. Association of the MscI polymorphism of the dopamine D3 receptor gene with tardive dyskinesia in schizophrenia. Neuropsychopharmacology, 21:17-27.

Basile VS, Ozdemir V, Masellis M, et al. 2000. A functional polymorphism of the cytochrome P450 1A2 (CYP1A2) gene: association with tardive dyskinesia in schizophrenia. Mol Psychiatry, 5:410-17.

Basile VS, Ozdemir V, Masellis M, et al. 2001. Lack of association between serotonin-2A receptor gene (HTR2A) polymorphisms and tardive dyskinesia in schizophrenia. Mol Psychiatry, 6:230-4.

Blasi G, Bertolino A. 2006. Imaging genomics and response to treatment with antipsychotics in schizophrenia. NeuroRx, 3:117-30.

Bradford D. 2002. CYP2D6 allele frequency in European Caucasians, Asians, Africans and their descendants. Pharmacogenomics, 3:229-43.

Brockmoller J, Kirchheiner J, Schmider J, et al. 2002. The impact of the CYP2D6 polymorphism on haloperidol pharmacokinetics and on the outcome of haloperidol treatment. Clinical Pharmacology and Therapeutics, 72:438-52.

Casey DE. 2004. Pathophysiology of antipsychotic drug-induced movement disorders. The Journal of Clinical Psychiatry, 65 (Supp1 9):25-8.

Chou WH, Yan FX, de Leon J, et al. 2000. Extension of a pilot study: impact from the cytochrome P450 2D6 polymorphism on outcome and costs associated with severe mental illness. J Clin Psychopharmacol, 20:246-51. 
Chouinard G. 2004. New nomenclature for drug-induced movement disorders including tardive dyskinesia. The Journal of Clinical Psychiatry, 65 (Suppl 9):9-15.

Dahl M-L. 2002. Cytochrome p450 phenotyping/genotyping in patients receiving antipsychotics: useful aid to prescribing? Clinical Pharmacokinetics, 41:453-70.

de Leon J, Armstrong SC, Cozza KL. 2005. The dosing of atypical antipsychotics. Psychosomatics, 46:262-73.

de Leon J, Armstrong SC, Cozza KL. 2006. Clinical guidelines for psychiatrists for the use of pharmacogenetic testing for CYP450 2D6 and CYP450 2C19. Psychosomatics, 47:1-12.

de Leon J, Susce MT, Murray-Carmichael E. 2006. The amplichip CYP450 genotyping test-integrating a new clinical tool. Mol Diag Ther, 10:135-51.

de Leon J, Susce MT, Pan RM, et al. 2005a. The CYP2D6 poor metabolizer phenotype may be associated with risperidone adverse drug reactions and discontinuation. Journal of Clinical Psychiatry, 66:15-27.

de Leon J, Susce MT, Pan RM, et al. 2005b. Polymorphic variations in GSTM1, GSTT1, PgP, CYP2D6, CYP3A5, and dopamine D2 and D3 receptors and their association with tardive dyskinesia in severe mental illness. Journal of Clinical Psychopharmacology, 25:448-56.

del Tacca M, Lattanzi L, Lastella M, et al. 2005. Genotype A1/A2 associated with neuroleptic malignant syndrome. Bipolar Disorders, 7:390-1.

Dorado P, Berecz R, Penas-Lledo EM, et al. 2006. Clinical implications of CYP2D6 genetic polymorphism during treatment with antipsychotic drugs. Current Drug Targets, 7:1671-80.

Eichhammer P, Albus M, Borrmann-Hassenbach M, et al. 2000. Association of dopamine D3-receptor gene variants with neuroleptic induced akathisia in schizophrenic patients: a generalization of Steen's study on DRD3 and tardive dyskinesia. American Journal of Medical Genetics (Neuropsychiatric Genetics), 96:187-91.

Ellingrod VL, Schultz SK, Arndt S. 2000. Association between cytochrome P4502D6 (CYP2D6) genotype, antipsychotic exposure, and abnormal involuntary movement scale (AIMS) score. Psychiatr Genet, 10:9-11.

Ellingrod VL, Schultz SK, Arndt S. 2002. Abnormal movements and tardive dyskinesia in smokers and nonsmokers with schizophrenia genotyped for cytochrome P450 2D6. Pharmacotherapy, 22:1416-19.

Ellingrod VL, Perry PJ, Ringold JC, et al. 2005. Weight gain associated with the $-759 \mathrm{C} / \mathrm{T}$ polymorphism of the $5 \mathrm{HT} 2 \mathrm{C}$ receptor and olanzapine. Am J Med Genetics Part B (Neuropsychiatric Genetics), 134B:76-8.

Ellingrod VL, Bishop JR, Moline J, et al. 2007. Leptin and leptin receptor gene polymorphisms and increases in body mass index (BMI) from olanzapine treatment in persons with schizophrenia. Psychopharmacology Bulletin, 40:57-62.

Freudenreich O, Goff DC. 2002. Antipsychotic combination therapy in schizophrenia: A review of efficacy and risks of current combinations. Acta Psychiatrica Scandinavica, 106:323-30.

Garcia-Barcelo MM, Lam LC, Ungvari GS, et al. 2001. Dopamine D3 receptor gene and tardive dyskinesia in Chinese schizophrenic patients. J Neural Transm, 108:671-7.

GovTrack, us, HR. 493 - 110th Congress (2007): Genetic Information Nondiscrimination Act of 2007, GovTrack.us (database of federal legislation). Accessed Jul 12, 2007. URL: http://www.govtrack.us/ congress/bill.xpd?bill=h110-493.

Guy W. 1976. Abnormal involuntary movement scale. In: ECDEU assessment manual for psychopharmacology. Washington, DC: U.S. Public Health Service. p 534-7.

Haro JM, Salvador-Carulla L. 2006. The SOHO (Schizophrenia Outpatient Health Outcome) study: implications for treatment of schizophrenia. CNS Drugs, 20:293-301.

Inada T, Dobashi I, Sugita T, et al. 1997. Search for a susceptibility locus to tardive dyskinesia. Hum Psychopharmacol Clin Exp, 12:35-9.

Ingelman-Sundberg M. 2004. Pharmacogenetics of cytochrome P450 and its applications in drug therapy, the past, present and future. Trends in Pharmacological Sciences, 24:193-200.
Janssen LP. Risperda $l^{\circledR}$ prescribing information [online]. Accessed 19 March 2007. URL: http://www.risperdal.com/active/janus/en_US/ assets/common/company/pi/risperdal.pdf.

Jeanneteau F, Funalot B, Jankovic J, et al. 2006. A functional variant of the dopamine D3 receptor is associated with risk and age at onset of essential tremor. PNAS, 103:10753-8.

Joy CB, Adams CE, Lawrie SM. 2006. Haloperidol versus placebo for schizophrenia. Cochrane Database of Systematic Reviews, (4):CD003082.

Kaiser R, Tremblay P-B, Klufmoller F, et al. 2002. Relationship between adverse effects of antipsychotic treatment and dopamine $\mathrm{D}$ [sub2] receptor polymorphisms in patients with schizophrenia. Molecular Psychiatry, 7:695.

Kapitany T, Meszaros K, Lenzinger E, et al. 1998. Genetic polymorphism for drug metabolism (CYP2D6) and tardive dyskinesia in schizophrenia. Schizophr Res, 32:101-6.

Kapur S, Seeman P. 2001. Does fast dissociation from the dopamine D2 receptor explain the action of atypical antipsychotics? Am J Psychiatry, 158:360-9.

Kirchheiner J, Nickchen K, Bauer M, et al. 2004. Pharmacogenetics of antidepressants and antipsychotics: the contribution of allelic variations to the phenotype of drug response. Molecular Psychiatry, 9:442-73.

Kishida I, Kawanishi C, Furuno C, et al. 2004. Association in Japanese patients between neuroleptic malignant syndrome and functional polymorphisms of the dopamine D2 receptor gene. Molecular Psychiatry, 9:293-8.

Lambert BL, Cunningham FE, Miller DR, et al. 2006. Diabetes risk associated with use of olanzapine, quetiapine and risperidone in veterans health administration patients with schizophrenia. American Journal of Epidemiology, 164:672-81.

Lane HY, Lee CC, Liu YC, et al. 2005. Pharmacogenetic studies of response to risperidone and other newer atypical antipsychotics. Pharmacogenomics, 6:139-49.

Lerer B, Segman RH, Fangerau H, et al. 2002. Pharmacogenetics of tardive dyskinesia. Combined analysis of 780 patients supports association with dopamine D3 receptor gene Ser9Gly polymorphism. Neuropsychopharmacology, 27:105-19.

Lerer B, Segman RH, Tan E-C. 2005. Combined analysis of 635 patients confirms an age related association of serotonin $2 \mathrm{~A}$ receptor gene with tardive dyskinesia and specificity for non-orofacial subtype. International Journal of Neuropsychopharmacology, 8:411-25.

Lerer B, Segman RH. 2006. Pharmacogenetics of antipsychotic therapy: pivotal research issues and the prospects for clinical implementation. Dialogues in Clinical Neuroscience, 8:85-94.

Lieberman JA, Stroup TS, McEvoy JP, et al. 2005. Effectiveness of antipsychotic drugs in patients with chronic schizophrenia. N Engl J Med, 353:1209-23.

Llerena A, Berecz R, Dorado P, et al. 2004. QTc interval, CYP2D6 and CYP2C9 genotypes and risperidone plasma concentrations. Journal of Psychopharmacology, 18:189-93.

Malhotra AK, Murphy GM Jr, Kennedy JL. 2004. Pharmacogenetics of psychotropic drug response. Am J Psychiatry, 161:780-96.

Mihara K, Kondo T, Suzuki A, et al. 2001. No relationship between-141C Ins/ Del polymorphism in the promoter region of dopamine D2 receptor and extrapyramidal adverse effects of selective dopamine D2 antagonists in schizophrenic patients: a preliminary study. Psychiatry Research, 101:33-8.

Mihara K, Kondo T, Suzuki A, et al. 2003. Relationship between functional dopamine D2 and D3 receptors gene polymorphism and neuroleptic malignant syndrome. American Journal of Medical Genetics Neuropsychiatric Genetics, 117:57-60.

Mihara K, Suzuki A, Kondo T, et al. 2001. Relationship between Taq1 A dopamine D2 receptor (DRD2) polymorphism and prolactin response to bromperidol. American Journal of Medical Genetics (Neuropsychiatric Genetics), 105:271-4.

Miller DD, Ellingrod VL, Holman TL, et al. 2005. Clozapine-induced weight gain associated with the $5 \mathrm{HT} 2 \mathrm{C}$ receptor $-759 \mathrm{C} / \mathrm{T}$ polymorphism. American Journal of Medical Genetics Part B. Neuropsychiatric Genetics, 133B:97-100. 
Miller DD, McEvoy JP, Davis S, et al. 2005. Clinical correlates of tardive dyskinesia in schizophrenia: baseline data from CATIE schizophrenia trial. Schizophrenia Research, 80:33-43.

Morley KI, Hall WD. 2004. Using pharmacogenetics and pharmacogenomics in the treatment of psychiatric disorders: some ethical and economic considerations. Journal of Molecular Medicine, 82:21-30.

Muller DJ, Kennedy JL. 2006. Genetics of antipsychotic treatment emergent weight gain in schizophrenia. Pharmacogenomics, 7:863-87.

Murray M. 2006. Role of CYP pharmacogenetics and drug-drug interactions in the efficacy and safety of atypical and other antipsychotic agents. Journal of Pharmacy and Pharmacology, 58:871-85.

Newcomer JW. 2006. Medical risk in patients with bipolar disorder and schizophrenia. J Clin Psychiatry, 67 (Suppl 9):25-30.

Ohmori O, Suzuki T, Kojima H, et al. 1998. Tardive dyskinesia and debrisoquine 4-hydroxylase (CYP2D6) genotype in Japanese schizophrenics. Schizophr Res, 32:107-13.

Olfson M, Blanco C, Liu L, et al. 2006. National Trends in the outpatient treatment of children and adolescents with antipsychotic drugs. Archives of General Psychiatry, 63:679-85.

Olfson M, Marcus SC, Corey-Lisle P, et al. 2006. Hyperlipidemia following treatment with antipsychotic medications. Am J Psychiatry, 163:1821-5.

Ozdemir V, Williams-Jones B, Cooper D, et al. 2007. Mapping translational research in personalized therapeutics. Pharmacogenomics, 8:77-85.

Regenold WT, Thapar RK, Marano C, et al. 2002. Increased prevalence of type 2 diabetes mellitus among psychiatric inpatients with bipolar I affective and schizoaffective disorders independent of psychotropic drug use. Journal of Affective Disorders, 70:19-26.

Reynolds GP, Templeman LA, Zhang ZJ. 2005. The role of 5-HT2C receptor in the pharmacogenetics of antipsychotic drug treatment. Progress in Neuro-Psychopharmacology and Biological Psychiatry, 29:1021-8.

Reynolds G, Templeman LA, Godlewska BR. 2006. Pharmacogenetics of schizophrenia. Expert Opinion on Pharmacotherapy, 7:1429-40.

Rietschel M, Krauss H, Muller DJ, et al. 2000. Dopamine D3 receptor variant and tardive dyskinesia. Eur Arch Psychiatry Clin Neurosci, 250:31-5.

Ryan MC, Collins P, Thakore JH. 2003. Impaired fasting glucose tolerance in first-episode, drug-naive patients with schizophrenia. The American Journal of Psychiatry, 160:284-9.

Sachse C, Brockmoller J, Baue S, et al. 1997. Cytochrome P450 2D6 variants in a Caucasian population: allele frequencies and phenotypic consequences. Am J Hum Genet, 60:284-95.

Schulze TG, Schumacher J, Muller DJ, et al. 2001. Lack of association between a functional polymorphism of the cytochrome P450 1A2 (CYP1A2) gene and tardive dyskinesia in schizophrenia. Am J Med Genet, 105:498-501.

Scordo MG, Spina E, Facciolà G, et al. 1999. Cytochrome P450 2D6 genotype and steady state plasma levels of risperidone and 9hydroxyrisperidone. Psychopharmacology, 147:300-6.

Segman R, Neeman T, Heresco-Levy U, et al. 1999. Genotypic association between the dopamine D3 receptor and tardive dyskinesia in chronic schizophrenia. Mol Psychiatry, 4:247-53.

Segman RH, Heresco-Levy U, Finkel B, et al. 2001. Association between the serotonin $2 \mathrm{~A}$ receptor gene and tardive dyskinesia in chronic schizophrenia. Mol Psychiatry, 6:225-9.
Shirzadi AA, Ghaemi SN. 2006. Side effects of atypical antipsychotics: extrapyramidal symptoms and the metabolic syndrome. Harvard Review of Psychiatry, 14:152-64.

Sipos FR, Kehoe PG, Burns T, et al. 2006. The cardiovascular and respiratory health of people with schizophrenia. Acta Psychiatrica Scandinavica, 113:245-6.

Srivastava V, Varma PG, Prasad S, et al. 2006. Genetic susceptibility to tardive dyskinesia among schizophrenia subjects: IV role of dopaminergic pathway gene polymorphisms. Pharmacogenetics and Genomics, 16:111-17.

Stahl SM, Grady MM. 2004. A critical review of atypical antipsychotic utilization: comparing monotherapy with polypharmacy and augmentation. Current Medicinal Chemistry, 11:313-27.

Steen VM, Lovlie R, MacEwan T, et al. 1997. Dopamine D3-receptor gene variant and susceptibility to tardive dyskinesia in schizophrenic patients. Mol Psychiatry, 2:139-45.

Suzuki A, Kondo T, Otani K, et al. 2001. Association of the Taq1 polymorphism of the dopamine D2 receptor gene with predisposition to neuroleptic malignant syndrome. Am J Psychiatry, 158:1714-16.

Swainston-Harrison T, Perry CM. 2004. Aripiprazole: a review of its use in schizophrenia and schizoaffective disorder. Drugs, 64:1715-36.

Tan EC, Chong SA, Mahendran R. 2001. Susceptibility to neurolepticinduced tardive dyskinesia and the $\mathrm{T} 102 \mathrm{C}$ polymorphism in the serotonin type 2A receptor. Biol Psychiatry, 50:144-7.

Tecott LH, Sun LM, Akana SF, et al. 1995. Eating disorder and epilepsy in mice lacking 5-HT2C serotonin receptors. Nature, 374:542-6.

Templeman LA, Reynolds GP, Arranz B, et al. 2005. Polymorphisms of the 5-HT2C receptor and leptin genes are associated with antipsychotic drug-induced weight gain in Caucasian subjects with a first-episode psychosis. Pharmacogenetics and Genomics, 15:195-200.

Tiwari AK, Desphande SN, Rao AR, et al. 2005. Genetic susceptibility to tardive dyskinesia in chronic schizophrenia subjects: III Lack of association of CYP3A4 and CYP2D6 gene polymorphisms. Schizophrenia Research, 75:21-6.

Van Brunt DL, Gibson PJ, Ramsey JL, et al. 2003. Outpatient use of major antipsychotic drugs in ambulatory care settings, Medgenmed [computer file]. Medscape General Medicine, 5:16. Accessed 15 August 2007. URL: http://www.medscape.com/viewarticle/458984.

Wilkaitis J, Mulvihill T, Nasrallah HA. 2004Classic antipsychotic medications. In: Schatzberg AF, Nemeroff CB eds. American psychiatric publishing textbook of psychopharmacology. 3rd ed. American Psychiatric Publishing. p 437.

Wilkinson GR. 2005. Drug metabolism and variability among patients in drug response. $N$ Engl J Med, 352:21.

Williams-Jones B, Ozdemir V. 2007. Challenges for corporate ethics in marketing genetic tests. Journal of Business Ethics advance online publication accessed 7/12/07 http://www.springerlink.com/content/ g6w320149833347h/?p=90f320134a9f4804b5bca7f6d3c3f60b\&pi=0

Young RM, Lawford BR, Barnes M, et al. 2004. Prolactin levels in antipsychotic treatment of patients with schizophrenia carrying the DRD2 allele. British Journal of Psychiatry, 185:147-51.

Zai CC, Hwang RW, De Luca V, et al. 2006. Association study of tardive dyskinesia and twelve DRD2 polymorphisms in schizophrenia patients. International Journal of Neuropsychopharmacology, 7:1-13. 
